Original Research

\title{
Self-Efficacy of Exercise in Older Adults with Diabetes: A Concept Analysis
}

\section{Somsak Thojampa', Chawapon Sarnkhaowkhom ${ }^{2}$, Sirikanok Klankhajhon' ${ }^{1}$, Roongtiva Boonpracom¹, Amaraporn Puraya ${ }^{1}$, and Wuttichai Sahattecho ${ }^{3}$}

${ }^{1}$ Faculty of Nursing, Naresuan University, Phitsanulok, Thailand

${ }^{2}$ Faculty of Nursing, Saint Louis College, Thailand

${ }^{3}$ Faculty of Management Science, Pibulsongkram Rajabhat University, Thailand

\begin{abstract}
Introduction: Self-efficacy is defined as a person's own judgment of their capabilities to perform a specific activity to attain a particular outcome. The concept of self-efficacy of exercise in older adults with diabetes may still be unclear, so it is essential to elucidate its meaning for better understanding in this concept. This paper aims to explore the meaning of self-efficacy with regard to exercise in older adults with diabetes.
\end{abstract}

Methods: Using the Walker and Avant concept analysis, it discusses cases showing diabetic Thai people and how they manage their health behavior changes, such as with exercise.

Results: Analysis of the concept of self-efficacy in terms of its defining attributes, antecedents, consequences, and empirical referents provides information related to clinical usefulness. It helps healthcare professionals communicate the same notion when discussing self-efficacy and can distinguish this concept from other related concepts.

Conclusion: Analysis of the concept of self-efficacy provides information related to exercise in older adults and can assist healthcare professionals in communicating the same notion when discussing the concept.

\section{ARTICLE HISTORY}

Received: May 15, 2020

Accepted: June 22, 2020

\section{KEYWORDS}

concept analysis; selfefficacy; diabetes; exercise

\section{CONTACT}

Somsak Thojampa $\triangle$ somsakth@outlook.com

$\supseteqq$ Faculty of Nursing, Naresuan University, Phitsanulok, Thailand

Cite this as: Thojampa, S., Sarnkhaowkhom, C., Khunkhajhon, S., Boonpracom R., Puraya A., \& Sahattecho, W. (2020). Self-Efficacy of Exercise in Older Adults with Diabetes: A Concept Analysis. Jurnal Ners, 15(1). 105-112. doi:http://dx.doi.org/10.20473/in.v15i1.19814

\section{INTRODUCTION}

Diabetes is a chronic disease that is becoming more common, especially among the elderly (Chentli, Azzoug, \& Mahgoun, 2015). The number of diabetics aged 65 years or older was projected to increase from 6.3 million in 2005 to 26.7 million by 2050 and the percentage of diabetic older persons was projected to increase from 39\% to 55\% (Caspersen et al., 2012). The global health predicts that, in 2030, diabetic patients will be 450 million globally (WHO, 2014). The number of persons living with DM in Asia was about 113 million in 2010, and this number is expected to increase to 180 million by 2030 (Chan et al., 2009). In Thailand, according to the Department of Disease Control (2012), the rate of diabetes in the elderly is $2,128.04$ per 100,000 population (Aekplakorn et al., 2011).

The World Health Organization (WHO) also claims that DM is an especially serious concern and becoming increasingly common in developing countries and among disadvantaged minorities
(WHO, 2014). The International Diabetes Foundation (IDF) reported that middle- and low-income countries have more people under the age of 60 with DM compared to the world average (IDF, 2014). Thailand was ranked among the top ten countries in Asia with a high prevalence rate of DM (Aekplakorn et al., 2011). Chronic hyperglycemia is a significant concern since it will lead to the progression of complications for an individual with DM. The complications of DM are the most significant contributing factor to the cost, since complications often require more intensive care in the hospital, or even may require surgery (Riewpaiboon et al., 2007).

Self-efficacy is one of the central concepts of Bandura's theory. The author believed that a fundamental requirement to organize and execute a series of actions is required to attain expected outcomes is by exploring and utilizing one's own capabilities, it is called "self-efficacy" (Bandura, 1997). It is an important concept because it predicts human behavior. The self-efficacy concept has been 
of considerable interest in several disciplines related to human behavior, such as nursing, sociology, and psychology. There are many authors that have misused this concept (Williams \& Rhodes, 2016). Bandura (1997) mentioned that some people used the terms 'self-efficacy' and 'self-esteem' interchangeably. However, they are different concepts and have various meanings. Although the concept of self-efficacy of exercise in older adults with diabetes may still be unclear, it is essential to elucidate its meaning for better understanding in this concept.

The term 'perceived self-efficacy' has been substituted in the literature to represent self-efficacy (Bandura, 1997). The definition of the word perceive is to attain awareness or understanding of or to become aware of through senses. Self-efficacy is defined as a person's own judgment of their capabilities to perform a specific activity in order to attain a particular outcome. The term perceives is implied in the definition of self-efficacy and does not change the meaning. In most dictionaries, the term 'self-efficacy' is presented as two words - 'self' and 'efficacy'. The term 'self' is quite easily understood, it is a person as the object of his or her own reflective consciousness (Kristen, 2009) while the term 'efficacy' is defined as the ability or power to produce desired things (Liu, 2012). This paper aims to conduct a concept analysis of self-efficacy with regard to exercise in older adults with diabetes.

\section{MATERIALS AND METHODS}

This concept analysis incorporated literature reviews from several healthcare disciplines, including nursing and medicine. The search for relevant articles was conducted utilizing databases including CINAHL, PubMed, Cochrane Database, and the medical database in Thailand (ThaiLIS and Thai Digital Collection (TDC)). The search criteria was set to include only articles in the past 14 years and available in English or in Thai languages. In addition, the search used the keywords 'self-efficacy', 'older adult', and 'exercise'. The search results were reduced to 1758 articles. Furthermore, after geographical restriction to Asia was applied, the results reduced to 64 articles. Finally, when the restriction to use self-efficacy as physical activity was applied, the results were reduced to 14 articles, which formed the basis of this review.

The Walker and Avant methodology (Walker \& Avant, 2010) was used for this concept analysis. There are eight steps in this method: selecting a concept; determining the aims or purpose of analysis; identifying all uses of the concept; determining the defining attributes; constructing a model case; constructing contrary, related and borderline cases; identifying antecedents, consequences; and defining empirical referents.

\section{Step 1: Select a concept}

Concept analysis is a process to explore the meaning, the definition and the attributes of a particular concept. The first step of the process is to select a concept. The concept of self-efficacy of exercise in people with diabetes was chosen for this paper.

\section{Step 2: Determine the aims or purpose of analysis}

The purpose of analyzing a self-efficacy concept is to provide a clear understanding and description of this concept. This can be accomplished by utilizing various analytical methodologies. This paper would like to clarify the meaning of self-efficacy in order to use the concept appropriately in further theoretical developments, particularly in exercise of diabetes people.

\section{Step 3: Identify all uses of the concept}

Exploring for meanings should start by searching from various sources because it helps in achieving the result from a significant amount of valuable information. The considering of all uses of the term, not only one aspect of the concept, is done by searching from various sources. Thus, dictionaries, thesauri, and available literature from a variety of disciplines, such as psychology, sociology, nursing, medicine, and epidemiology, etc., were all employed to identify uses of the concept (Walker \& Avant, 1995).

Self-efficacy is defined as a person's belief about their competence to complete tasks and reach goals (Bandura, 1997). Bandura (1997) mentions that selfefficacy can be achieved by learning through personal experiences, observing others' behavior and performance, following verbal persuasion, and controlling physiological arousals.

There are many authors who have provided definitions of self-efficacy. Kristen (2009), for example, defined self-efficacy as “a person's own judgment of capabilities to perform a certain activity in order to attain a certain outcome." Edberg (2007) defined self-efficacy as "a person's confidence that he or she can perform a behavior." Glanz, Rimer, and Viswanath (2008) stated "self-efficacy is a person's beliefs about his or her capacity to influence the quality of functioning and the events that affect their lives", while Lowenstein, Foord-May, and Romano (2009) defined it as "the degree of confidence a person has that he or she can perform a certain behavior and overcome any barriers that may impede progress." From reviewing available literature, it was found that most studies measure self-efficacy through respondent's confidence in their capabilities.

In summary, self-efficacy is commonly defined as the belief in one's capabilities to achieve a goal or an outcome and the word 'efficacy' can be applied to both human beings and objects. Both cases are quite similar. They refer to the inherent attributes, which 
is the meanings of 'efficacy'. Most dictionaries have a similar definition for the term 'self-efficacy' as a person's own judgment of their capabilities to perform a particular activity in order to attain a certain outcome. The ability to recognize, which includes the affirmation and the strength, to produce effects in a particular task is a sense of self-efficacy. Furthermore, the definitions as described in this paper help provide useful insights about selfefficacy.

\section{Step 4: Determine the defining attributes}

There were five defining attributes of self-efficacy that have been extracted from the literature: resources, knowledge, active participation, adherence to a self-efficacy plan as well as informed decision-making. These attributes compose a defined structure which represents the concept of selfefficacy.

\section{Resources}

Resources and knowledge form the foundation of self-efficacy. Without proper resources and updated knowledge, it is impossible to carry out the selfefficacy tasks. The HCP should offer medical advice, support, and guidance to the individual living with chronic disease as part of the resource pool (Huffman, 2005). In Thailand, resources for selfefficacy intervention programs for persons with chronic diseases include local community health centers and local healthcare volunteers (Srichairattanakull et al., 2014). There are local healthcare volunteers for every local community, such as in a village (Wanitkun et al., 2011). Support from family members, healthcare providers, and friends enhances adherence to self-care behaviors in Thai people with cardiovascular disease (CAD) (Khuwatsamrit et al., 2006).

\section{Knowledge}

Knowledge can be obtained through education or through personal experience as well as from development of expertise (Cameron et al., 2010). Without proper knowledge, individuals with chronic diseases are unable to effectively participate in their self-efficacy (Tanner, 2004). In Thailand, knowledge of the disease and how to treat and prevent it are obtained mainly through health education and health promotion programs by the hospitals (Deesiang \& Preechawong, 2008). Patients are usually assigned to a focus group wherein health promotion and health education is conducted in a hospital (Suwankruhasn et al., 2013).

\section{Active Participation}

Active participation refers to achieving a balance between adherence and a person's need to be responsible for his or her own care (Cohen, 2009). This active participation is demonstrated by the patient's lifelong behavioral changes which are required for an individual with chronic disease (Tanner, 2004). Activities such as exercise, dietary control, keeping appointments and following instructed self-care represent the patients' commitment and their own desire to be active and responsible participants in the self-efficacy of their own disease (Brody et al., 2005). In Thailand, family support is most important for the patient. With solid family support, a patient can carry out any challenging medical treatment processes, including self-efficacy programs (Srichairattanakull et al., 2014).

\section{Adherence to a Plan}

Adherence to a plan requires that the patient follows a prescribed medical regimen prescribed by his or her HCP (Funnell \& Anderson, 2004). Taking prescribed medications appropriately and correctly is the most common measured outcome of adherence in the reviewed literature (Gould \& Mitty, 2010). In Thailand, nurses and local healthcare volunteers will prompt patients to adhere to a plan by either making a phone call or paying a home visit (Srichairattanakull et al., 2014). Several times, the local health volunteers will remind patients to follow instructions from their doctors.

\section{Informed Decision-making}

Informed decision-making is the outcome of having adequate resources, proper knowledge, active participation and adherence to a plan. Informed decision-making enables an individual with a chronic disease to make the best possible choices and deploy self-efficacy strategies on a daily basis (Lorig \& Holman, 2003). Informed decision-making puts the individual with chronic disease in control (Funnell \& Anderson, 2004). This is less frequent in Asia where most patients still rely on their HCP, mainly their doctors, to make decisions for them. Moreover, Thai patients trust and respect their doctors the most (Wanitkun et al., 2011).

\section{Step 5: Construct a model case}

A model case is an example of the use of the concept that demonstrates all its defining attributes. That is, the model case should be a pure case of the concept, a paradigmatic example, or a pure exemplar (Dugger, 2010; Walker \& Avant, 2005). To clarify the concept, a model case of self-efficacy is illustrated as follows:

Mr. Mo is a 76-year-old man, who exercises every day. He began exercising since he was 70 years old or six years ago. He had diabetes diseases and also had a right leg limp and was hospitalized once at the age of 71. He was hospitalized for three days. After he came back home, a community nurse visited him and gave some advice and discussed with him about the benefits of exercise and gave him examples of how exercise helped to improve the health of other patients. Despite his old age and his illness, he 
believes that exercise is the best way for recovering from his disease.

Mr. Mo also intends to learn about good exercising experiences from his friends. Finally, he has strong beliefs in his ability and the advantages of exercise, so he decided to participate in an exercise program. He began doing exercise by walking slowly, but limited his walking to 50 feet.

Although sometimes he gets hurt from doing exercise, he continues to do exercise every day. Every morning when he wakes up, he tells himself, "I have to walk soon, I can do it", and he intends to exercise every morning.

After one month, he said, "Before I began exercising, I was worried about my old age because I think that I cannot exercise and I have pains in nearly every joint, but now I am feeling better." And now, he has become more active in his local senior citizen's group because he has a positive feeling towards exercise.

In addition, he believed that if he intended to exercise, he would succeed in walking one mile like others in his age bracket. His commitment was to go out for a walk every morning and gradually increase the distance that he walked. Eventually, he was able to walk one mile like others in his age bracket. After two years of doing exercise, he walks one mile every morning, and he does not need medication to relieve pains. Mr. Mo demonstrated all of the defining attributes of self-efficacy. He had clear goals and an obvious confidence in his capabilities.

These characteristics were illustrated in his decision to participate in the exercise program. The strength, affirmation of his confidence, perseverance, and mastery of experience were seen through his exercise goal and practice. He was persistent in his efforts. Although he was in pain, he overcame the difficulty in walking at the beginning of his exercise program. In addition, he did the task with a strong sense of commitment to himself.

\section{Step 6: Constructing the contrary, related and borderline cases}

\section{Construct a contrary case}

Walker and Avant (2005) stated that contrary cases are clear examples of 'not the concept', but they are accommodating to understand the concept easily by excluding all its defining attributes. The following case is undoubtedly an example of a person with very poor self-efficacy expectations, devoid of all critical attributes of self-efficacy (Dugger, 2010).

Mrs. Kik is a 74-year-old woman who was diagnosed as having diabetes with arthritis in both knees. She was hospitalized for three days. After she came home, a community nurse visited her and gave her some advice and discussed with her about the benefits of exercise and examples of how exercise helped improve the health of other patients.

Although a community nurse gave some suggestions about the exercise programs, Mrs. Kik ignored the recommendations. She said, "At my age, I want to rest, I cannot do anything much, I had pains in both of my knees, and I cannot walk and run like a young woman."

This case does not explain and exhibit defining attributes of self-efficacy. Because she lacks confidence in her own abilities and she thought that her age was a barrier to doing exercise, she did not persist in her efforts to participate in exercise activities or even show a first attempt to exercise.

\section{Construct a related case}

The related cases are similar to the concept of selfefficacy, but do not explain all of the defining attributes. Those terms, which appear to be used often and are related to self-efficacy, are as follows: self-esteem, self-concept, self-control, selfactualization, self-confidence, health locus of control, perceived competence and perceived self-care agency. The related case of self-confidence described below is distinguishable from self-efficacy.

Mr. Pongsit is a 72-year-old man. He has diabetes with an arthritic limp and was hospitalized for a week. After coming back home, a community nurse visited him and talked to him about exercising benefits. She gave suggestions about an exercise program, and she tried to explain that an exercise program will help reduce the severity of his symptoms.

After that, he decided to participate in an exercise program with confidence in his abilities. When he began to exercise by strolling, he limited his walking to 50 feet. He complained to his nurse that he was hurting more. He thought that it was caused by doing exercise and he did not want to attempt it anymore. He wanted to quit exercising. Although a community nurse has explained the process of the pain is caused by the disease and convinced him to continue exercising, he still wants to quit exercising.

This case does not contain all of the defining attributes of self-efficacy. Mr. Pongsit has confidence in his ability; however, he does not demonstrate an affirmation of confidence in his belief in his ability to overcome the difficulties in order to achieve the goal.

\section{Construct a borderline case}

Mrs. Susan, who is 72 years old, fell from her bed. She has diagnosed diabetes with having fractured her hip and was hospitalized for a month. After being discharged from the hospital, the nurse suggested that she rehabilitated herself in a nursing home since her husband may not be able to take care of her due to his deteriorating health. However, although her husband is 75 , he insists that he will be able to handle it. Although the nurse has explained the complexity of care that will be necessary, he believes that he is able to provide care for his wife. He helps his wife to do passive exercise every day, but it is less effective. His ongoing attempt to learn how to rehabilitate her correctly causes further harm to her healing process. 
Table 1. The summary of the Concept Analysis of Self-Efficacy of Exercise in Older Adults with Diabetes: Attributes, Antecedents, and Consequences

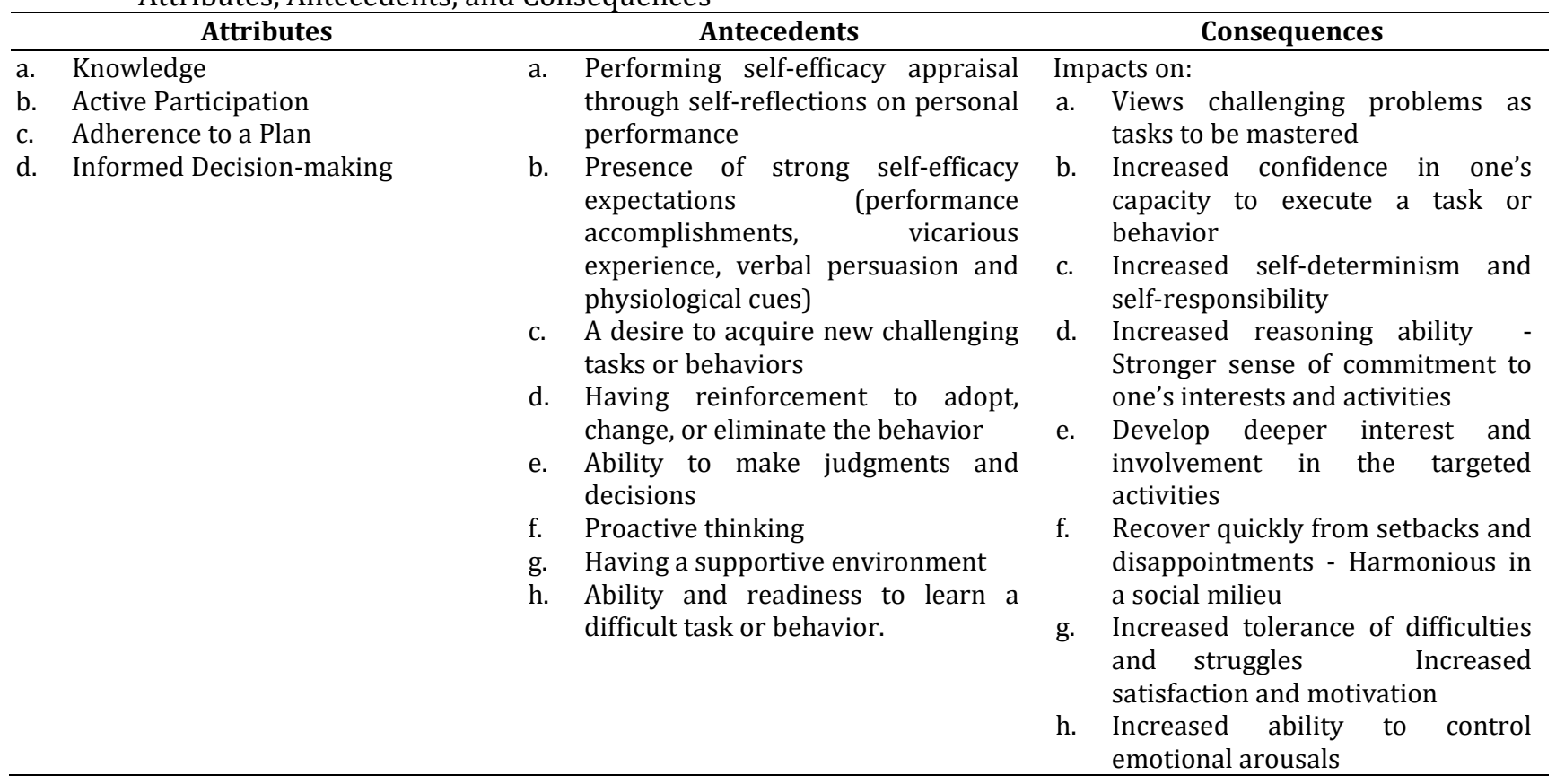

This case demonstrates some of the defining attributes of the concept of self-efficacy. The strength of her husband's confidence in his ability to care for his wife is shown by his insistence that he would be able to perform the required tasks. He also illustrated his confirmation of confidence as he tried to master the passive exercise. However, he lacks the capability to learn how to successfully heal his wife through passive exercise.

\section{Step 7: Identifying antecedents and consequences}

\section{Identify antecedents}

Walker and Avant (2005) suggested that antecedents are those events that must occur prior to the occurrence of the concept. The antecedents of selfefficacy (Nyi Nyi Htay, 2010) that arise from the literatures are: 1) Performing self-efficacy appraisal through self-reflections on personal performance; 2) Presence of strong self-efficacy expectations (performance accomplishments, vicarious experience, verbal persuasion and physiological cues); 3) A desire to acquire new challenging tasks or behaviors; 4) Having reinforcement to adopt, change, or eliminate the behavior; 5) Ability to make judgments and decisions; 6) Proactive thinking; 7) Having a supportive environment; and 8) Ability and readiness to learn a difficult task or behavior.

\section{Identify consequences}

Walker and Avant (2005) stated that consequences are those events or incidents that occur as a result of the occurrence of the concept. According to the result of literature analysis, the consequences of a robust self-efficacy encompass the following: Views challenging problems as tasks to be mastered, Increased confidence in one's capacity to execute a task or behavior; increased self-determinism and self-responsibility; increased reasoning ability; stronger sense of commitment to one's interests and activities; develop deeper interest and involvement in the targeted activities; recover quickly from setbacks and disappointments; harmonious in a social milieu; increased tolerance of difficulties and struggles; increased satisfaction and motivation; and increased ability to control emotional arousals (Nyi Nyi Htay, 2010).

\section{Step 8: Define empirical referents}

Determining the empirical referents is extremely useful in instrument development because these are categories of phenomena whose presence demonstrate the occurrence of the concept (Dugger, 2010; Walker \& Avant, 2005). In a standard way to measure the performance of beliefs, individuals are presented with items of progressively more difficult performance requirements within a particular behavioral domain (Bandura, 1997). People's beliefs and commitment are difficult to measure. The items are phrased in terms of whether they can or cannot perform the specific behavior. The strength and affirmation of an individual's confidence to overcome difficulties are rated on a 100-point scale, ranging in 10-unit intervals from 0 to 100 . Recently, several scales have been developed for health behaviors, such as physical activity, and have shown to have good reliability and validity (Sallis, 1988).

Nyi Nyi Htay (2010) shows that various quantitative and qualitative studies are necessary to clarify and validate the empirical referents of selfefficacy, using structured questionnaires, 
observations, interviews, focus group discussions and review of the method that it is appropriate to define the concept of self-efficacy. The study and analysis of literary evidence are needed to confirm the reliability and accuracy of these referents.

Analysis of the concept of self-efficacy in terms of its defining attributes, antecedents, consequences, and empirical referents provides information related to clinical usefulness. It helps healthcare professionals communicate the same notion when discussing self-efficacy and can distinguish this concept from other related concepts.

\section{RESULTS}

The concept of self-efficacy was analyzed in terms of its defining attributes, antecedents and consequences, and empirical referents provide information related to clinical usefulness following the steps of concept analysis. The meaning of selfefficacy in order to use the concept appropriately in further theoretical developments, particularly in exercise of diabetics was explored. Data were extracted from the literature: resources, knowledge, active participation, adherence to a self-efficacy plan and informed decision-making. The related cases are similar to the concept of self-efficacy, but do not explain all of the defining attributes. Those terms, which appear to be used often and are related to selfefficacy, are as follows: self-esteem, self-concept, self-control, self-actualization, and self-confidence, health locus of control, perceived competence and perceived self-care agency. The related case of selfconfidence described below is distinguishable from self-efficacy. It helps healthcare professionals communicate the same notion when discussing selfefficacy and can distinguish this concept from other related concepts. See Table 1.

\section{DISCUSSION}

Self-efficacy is a basic idea to develop a healthy and productive society. It is one of the best strategies for a challenging task or behavior with the ability to recognize the people and to learn through observation. Self-efficacy refers to an individual's perception of his or her ability to conduct certain acts without other people's help. Strong desire, motivation, and ability are a few aspects of selfefficacy. Patients' confidence in their ability to modify their behavior and perform self-management and self-monitoring will impact the outcome of the self-management, including maintaining those changed behaviors (Urmimala et al., 2009). While self-efficacy is more emphasized in the West, family support is more common in the East (Wanitkun et al., 2011). In Asia, including Thailand, patients will rely on their family members to 'take care' of them when they are ill or getting old. Parents expect their adult children to take care of them when they are in need (Wattanakul, 2012).

Even though more individuals with DM participated in or started 'regular exercise' (definition varied in different studies) after being diagnosed with having DM (Kongsap \& Methakanjanasak, 2012, Mosnier-Pudar et al., 2009), not every individual with DM realizes the importance of physical activity (PA) for their selfmanagement of the disease. It is reported by Houle et al. (2015) that completely stopping any exercise or PA after being physically active in their base study was associated with a rise in their HbA1c level at 6month follow-up (Houle et al.,2015).

People must have a sense of efficacy in the maintenance of the perseverant effort needed to succeed. This paper is an attempt to explain the concept of self-efficacy, by examining its meanings, antecedent, consequences, usages and empirical referents, including an illustration of the model case and the contrary case. Based on the results of the analysis, operation of self-efficacy was developed.

Symptoms of a dry mouth due to reduced saliva can make a patient feel uncomfortable. disturb the appetite and quality of life (Plemons et al., 2014). Study (Dental \& Ada, 2015) states sucking ice cubes, drinking water while eating to help chew and swallow food, using mouthwash-free mouthwash, avoiding carbonated drinks (such as soda), caffeine, tobacco, and alcohol, and using lanolin-based lip balm to comfort cracked or dry lips can reduce dryness in the mouth and stimulate saliva discharge. Increased salivary secretion leads to increased volume and thinning of saliva needed for ingestion and lubrication.

In this study, not all of the patients' salivary volumes increased. This is influenced by several factors. According to Samuels (2017) drugs, smoking, and alcohol consumption will reduce the flow rate of saliva. Most respondents were aged in the range 46-65 years. Old age will make the function of the salivary glands decrease, because the acinar element turns into fat and fibrous tissue (Baird, Donehower, Stalsbroten, \& Ades,1991).

The results of this study prove that the chewing gum and cryotherapy affect the stimulus production of saliva. Hopefully, this study can increase information about nursing care in head and neck cancer, so that the symptoms caused by radiotherapy of the head and neck area can be reduced or avoided.

The limitation of this study was the researcher cannot fully control the respondent's intervention because it is done at home or boarding so this can have an impact on the result of the study. The strength of this study was there is an effective nonpharmacological action nurses can take to increase the volume of saliva in head and neck cancer patients by chewing gum.

\section{CONCLUSION}

There is a noticeable variation of applying the concept of self-efficacy for the study of Exercise in Older Adults with Diabetes, particularly in Thailand (Wanitkun et al, 2011). More research is needed to 
explore all aspects of self-efficacy, particularly from Asian or Thai culture and religious perspectives (Wattanakul, 2012). This paper suggested a revised definition of the concept from a Thai cultural point of view. This revised concept of self-efficacy can be used accurately for the evaluation of the effectiveness of a self-efficacy intervention program in Thailand, with the aim for positive improved behavioral change, reduced healthcare expenditures as well as for improved quality of life.

\section{REFERENCES}

Aekplakorn, W., Chariyalertsak, S., Kessomboon, P., Sangthong, R., Inthawong, R.,Putwatana, P., \& Taneepanichskul, S. (2011). Prevalence and management of diabetes and metabolic risk factors in Thai adults: The Thai National Health Examination Survey IV, 2009. Diabetes Care, 34(9), 1980-1985. https://doi.org/10.2337/dc110099

Bandura A.(1997). Self-efficacy: The exercise of control. New York: Freeman.

Cameron, J., Worrall-Carter, L., Page, K., \& Stewart, S. (2010). Self-care behaviors and heart failure: Does experience with symptoms really make a difference? European Journal of Cardiovascular Nursing: Journal of the Working Group on Cardiovascular Nursing of the European Society of Cardiology, 9(2), 92-100. https://doi.org/10.1016/j.ejcnurse.2009.10.004

Chan, J. C. N., Malik, V., Jia, W., Kadowaki, T., Yajnik, C. S., Yoon, K., \& Hu, F. B. (2009). Diabetes in Asia: Epidemiology, risk factors, and pathophysiology. Jama, 301(20), 2129-2140. https://doi.org/10.1001/jama.2009.726

Caspersen, C. J., Thomas, G. D., Boseman, L. A., Beckles, G. L., \& Albright, A. L. (2012). Aging, diabetes, and the public health system in the United States. American journal of public health, 102(8), https://doi.org/10.2105/AJPH.2011.300616

Chentli, F., Azzoug, S., \& Mahgoun, S. (2015). Diabetes mellitus in elderly. Indian journal of endocrinology and metabolism, 19(6), 744-752. https://doi.org/10.4103/2230-8210.167553

Deesiang, W. \& Preechawong, S. (2008). Effectiveness of self- management program on LDL cholesterol level of type 2 Diabetic Patients. Journal of Nursing Science Chulalongkorn University,20(2), 27-39.

Dugger B.(2010). Concept analysis of health related quality of life in nursing home residents with urinary incontinence. Journal of urologic nursing, 30,112-118.

Edberg, M. (2007). Essentials of Health Behavior: Social and Behavioral Theory in Public Health, Jones and Bartlett Publishers, Boston,52-55.

Glanz, K., Rimer, B.K., \& Viswanath, K. (2008). Health Behavior and Health Education:

Theory, Research, and Practice (4th ed.). John Wiley \& Sons, Inc., San Francisco, 97-121.
Huffman, M. H. (2005). Compliance, health outcomes, and partnering in PPS: Acknowledging the patient's agenda. Home Healthcare Nurse, 23(1), 23-28.

International Diabetes Federation (IDF).(2014). Diabetes in Thailand. Retrieved September 14,2015:

http://www.idf.org/membership/wp/thailand

Kristen, Z. (2009). Self-efficacy: A concept analysis. Nursing Forum, 44 (2): 93-102.

Khuwatsamrit, K., Hanucharurnkul, S., Chyun, D., Panpakdee, O., Tanomsup, S., \& Viwatwongkasem, C. (2006). Social support, self-efficacy, and adherence to self-care requirements in patients with coronary artery disease. Administrative Advisory Board, 156, 155-164.

Lowenstein, A.J., Foord-May, L., \& Romano, J.C. (2009). Teaching Strategies for Health Education and Health Promotion: Working with Patients, Families, and Communities. Jones and Bartlett Publishers, Boston, pp. 310-313.

Nyi Nyi Htay. (2010). Self-efficacy and concept analysis. Retrieved September 14, 2015: http://nyinyiuonmdymyanmar.blogspot.com/201 1/09/self-efficacy-concept-analysis.html.

Riewpaiboon, A., Pornlertwadee, P., \& Pongsawat, K. (2007). Diabetes cost model of a hospital in Thailand. Value in Health (Wiley-Blackwell), 10(4), 223-230.

https://doi.org/10.1111/j.15244733.2007.00172 .X

Sallis JF, Pinski RB, Grossman RM, Patterson TL, Nader PR(1988). The development of self-efficacy scales for health-related diet and exercise behaviors. Health Education Research,3,283-292.

Srichairattanakull, J., Kaewpan, W., Powattana, A., \& Pichayapinyo, P. (2014). Self management improvement program combined with community involvement in thai hypertensive population: An action research. Journal of the Medical Association of Thailand Chotmaihet Thangphaet, 97(4), 456-466.

Tanner, EK. (2004). Home health care. Chronic illness demands for self-management in older adults. Geriatric Nursing, 25, 313-317

Walker LO, Avant KC (1995). Strategies for theory construction in nursing. $3^{\text {rd }}$ ed. CT: Appleton \& Lange.

Wannipa Asawachaisuwikrom (2002). Concept analysis. Thai Journal nursing, 6,242-247.

Wanitkun, N., Batterham, R., Vichathai, C., Leetongin, G., \& Osborne, R. H. (2011).

Building equity in chronic disease management in Thailand: A whole-system provincial trial of systematic, pro-active chronic illness care. Chronic Illness, 7(1), 31-44. https://doi.org/10.1177/1742395310389495

Williams, D. M., \& Rhodes, R. E. (2016). The confounded self-efficacy construct: conceptual 


\section{S. THOJAMPA ET AL}

analysis and recommendations for future research. Health psychology review, 10(2), 113-128. https://doi.org/10.1080/17437199.2014.941998

World Health Organization (WHO) (2015). Diabetes mellitus. Retrieved September 14,2015: http://www.who.int/mediacentre/factsheets/fs13 8/en/ 